\title{
Candidate Traits in Elections: When Good News for Selection is Bad News for Accountability
}

\author{
Keith Schnakenberg*
}

\begin{abstract}
We analyze a two-election political agency model with moral hazard and adverse selection in which candidates have observable traits such as job qualifications that help voters to imperfectly predict politicians' types. Candidate's traits can help voters select good types of politicians. However, selecting candidates with good traits can reduce accountability because the voter cannot commit to throw out politicians with good traits who produce bad outcomes. This result explains when and why voters may sometimes select candidates who they believe are less likely to be competent.
\end{abstract}

Word count (appendix not included):

Words in text: 3561

Words in headers: 41

Words outside text (captions, etc.): 250

Number of headers: 10

Number of floats/tables/figures: 1

Number of math inlines: 115

Number of math displayed: 1

*Assistant Professor, Washington University in St Louis. 
Elections may produce responsive government either by selecting good politicians or by holding them accountable through the possibility of reelection. In political agency models both functions typically result from voters updating their beliefs about qualities of the incumbent politician based on their performance. ${ }^{1}$ This creates positive selection effects by making good types of politicians more likely to be retained and also incentivizes politicians to perform well in order to signal that they are good types. However, as Fearon (1999) noted, voters may learn about untried politicians based on "information about the personal character of a politician" that may be available prior to her initial election. We refer to these pieces of personal information as traits. Traits also play a role in empirical work where ex ante measures of candidate quality are important for explaining the incumbency advantage, the role of primaries, and other electoral outcomes. ${ }^{2}$

This paper analyzes the role of candidate traits in a simple political agency model. In the model, traits are publicly observable characteristics that correlate with candidate's types. Types are unobservable characteristics of interest such as competence, congruence, or trustworthiness. Good types of politicians are more likely to act in the voter's best interests but the voter's information about incumbent's choices is noisy. The intuitive understanding of traits is that they aid voters in selecting good candidates by helping them make better inferences about politicians' types. Our analysis supports this role of traits but also introduces another: Candidates with good traits may be less accountable to the voter because poor performance in office is not enough to convince the voter that the incumbent is a bad type. In some cases, this effect is large enough to make the voter prefer candidates with bad traits despite the fact that they are more likely to be bad types. This effect is most likely when the signal provided by candidate traits is moderately strong, when voters' signals about incumbent performance are quite noisy, and when the pool of candidates for office is poor.

One contribution of this paper is to show how accountability concerns may lead voters to select candidates who are ex ante less likely to be good types. Though my argument is new to the literature some previous work makes similar points from very different models. Kartik and Van Weelden (2018) shows that voters may select politicians who reveal themselves to be bad types because these politicians do not have an incentive to pander. The mechanism in this paper, however, is very different from their result. In Kartik and Van Weelden (2018) politicians' incentives to signal to voters are in conflict with acting in the voters' bests interests. Thus, voters may prefer a politician who has revealed herself to be a bad type because this politician cannot gain by signaling. The mechanism in this paper is the reverse: signaling incentives are

\footnotetext{
${ }^{1}$ See Berganza (2000); Besley (2006); Ashworth and de Mesquita (2014); Ashworth (2005).

${ }^{2}$ See Hirano and Snyder (2014); Carson, Engstrom and Roberts (2007).
} 
good for the voter because they cause the politician to work hard. When the candidate's reputation with the voter is already sufficiently good, that candidate may rest on her laurels rather than work hard to impress the voter. Thus, the voter may sometimes prefer politicians who are less likely to be good types but who have stronger incentives to impress the voter. ${ }^{3}$

An important mechanism driving results in this paper is that the politicians' incentives to exert effort may be reduced when they have a good reputation with the voter. A similar mechanism is also present in an otherwise much different model in Ashworth (2005). In that study, politicians reduce effort allocation later in their careers as they become more confident in their reelection prospects. This effect does not lead voters to prefer less competent candidates in that paper. In fact, a key result in that paper is that incumbency advantages arise due to positive selection effects.

\section{The model}

Consider a three-period model involving a representative voter (V), two initial candidates for office (1 and 2), and a second-period challenger (3). Prior to the first period, nature independently draws the types $\theta_{1}$ and $\theta_{2}$ of the initial candidates to be either $\mathrm{G}$ (good) or B (bad). The probability that any candidate is a Good type is $\operatorname{Pr}\left[\theta_{j}=G\right]=p$ for $j \in\{1,2\}$. Nature also chooses some observable trait of each candidate $j$, denoted $s_{j} \in\{g, b\}$ from a type-dependent distribution and reveals that trait to the voter. For simplicity, we assume that $\operatorname{Pr}\left[s_{j}=g \mid \theta_{j}=G\right]=\operatorname{Pr}\left[s_{j}=b \mid \theta_{j}=B\right]=q>\frac{1}{2}$. The variable $s_{j}$ can be thought of as one of the usual indicators of candidate quality or competence, such as whether or not that candidate has held previous office or whether she is endorsed by a local newspaper. When $s_{j}=g$ we say that candidate $j$ has good traits and when $s_{j}=b$ we say that candidate $j$ has bad traits. The voter observes $s_{1}$ and $s_{2}$ and then selects a candidate to elect to office for the second period. For the sake of completeness we assume that the voter breaks indifference in the first period by flipping a fair coin.

In the second period, the winning candidate takes office and takes an action $x_{2} \in\{0,1\}$. We think of $x_{2}=1$ as the desirable action from the perspective of the voter, which could represent abstaining from corruption, working hard while in office, or choosing policies in the voter's best interests. For both $t=2$ and $t=3$ we will refer to $x_{t}$ as effort and $x_{t}=1$ as high effort. However, the politician's action is not observed

\footnotetext{
${ }^{3}$ The result is also related to, but quite different from, a result found in Buisseret and Prato (2016) in which voters may also prefer lower ability politicians. In that paper the result follows from the fact that politician ability may be used to pursue multiple tasks and may cause them to focus on tasks that are less productive for the voter. An important difference in this paper is that voters in our model would never prefer a lower type of politician if they knew politicians' types with certainty.
} 
by the voter. Instead, the voter observes an outcome $y_{2} \in\{0,1\}$ which is correlated with $x_{2}$. To keep things simple, we assume that $y_{2}=1$ with some positive probability $r$ if $x_{2}=1$ and otherwise $y_{2}=0$. The voter observes $y_{2}$ and decides whether to retain the incumbent politician for period 3 or instead replace her with an untried challenger. The challenger is also a Good type with probability $p$ but the voter does not observe any other information about the challenger. ${ }^{4}$

In the third period, the politician selected for office takes an action $x_{3} \in\{0,1\}$ and the third period outcome $y_{3} \in\{0,1\}$ is realized, where again $y_{3}=1$ with probability $r$ if $x_{3}=1$ and $y_{3}=0$ otherwise. Finally $y_{3}$ is observed by the voter and the game ends.

The payoff of the voter is the sum of the second and third period outcomes. Politicians are office motivated by may pay a cost of taking the high action in office. Thus, politician j's payoff in a single period is

$$
u_{j t}\left(y_{t}\right)= \begin{cases}1-c\left(x_{t}, \theta_{j}\right) & \text { if } \mathrm{j} \text { holds office at time } \mathrm{t} \\ 0 & \text { otherwise. }\end{cases}
$$

The politician's total payoff is then $u_{j 2}\left(y_{2}\right)+u_{j 3}\left(y_{3}\right)$. We assume that taking the high action is costly only for the Low type, so $c(1, G) \leq c(0, G)=c(0, B)=0$ and $c(1, B)=k>0$.

We characterize perfect Bayesian equilibria to the game and we focus on weakly undominated strategies. A strategy for the voter is a plan for how to vote in the first period given the public information about both candidates and in the second period given the public information about the incumbent as well as the second period policy outcome. These strategies are labelled $\sigma_{V}^{1}\left(s_{A}, s_{B}\right)$ and and $\sigma_{V}^{2}\left(s_{j}, y_{2}\right)$ respectively, where $j$ here references the incumbent politician. Given our assumptions about candidate preferences the High type will choose $x_{t}=1$ any time she is in office. Furthermore, since there is no election after period 3, actions follow directly from types, with Good types choosing $x_{3}=1$ and Bad types choosing $x_{3}=0$. Thus, we will take these actions for granted and consider a politician's strategy only as the probability of choosing $x_{2}=1$ if she takes office as a Bad type, which sill be a function of $s_{j}$. Our focus will be on equilibria in which A and B play symmetric strategies so we simply denote this mixed strategy as $\sigma_{L}(s)$.

\footnotetext{
${ }^{4}$ Since there is no accountability in the last period, traits do not play the same role in the second-period election as they do in the initial election. For this reason, revealing traits of the second-period cNetwork 4hallenger would complicate our calculations without adding much insight.
} 


\section{Analysis}

We will analyze the game backwards. Since third period policy choices are already given, we start with the second-period choices and moving to the first-period election choice.

\subsection{Second-period game}

The second-period game begins with an incumbent with known traits. The incumbent chooses a level of effort but the voter only observes the outcome before deciding whether or not to retain the incumbent. Given a random challenger, the voter retains the incumbent only if she believes that the incumbent is a Good type with a probability weakly higher than the prior probability $p$ of a Good type. Good types of incumbents always give high effort and Bad types give high effort only if doing so increases their probability of reelection by more than the cost of effort. Specifically, the Bad type of incumbent $j$ gives high effort only if $\operatorname{Pr}\left[\right.$ reelected $\left.\mid s_{j}, x_{2}=1\right]-\operatorname{Pr}\left[\right.$ reelected $\left.\mid s_{j}, x_{2}=0\right] \geq k$.

These facts give rise to three types of equilibria, which we label pure selection, partial accountability, and accountability. In a pure selection equilibrium, no Bad type ever gives high effort. In a partial accountability equilibrium, Bad types with bad traits sometimes give high effort but Bad types with good traits never do so. Finally, in an accountability equilibrium, all Bad types give high effort with some probability. Proposition 1 summarizes these equilibria.

Proposition 1. Consider continuation game beginning with an incumbent in office in the second period. The equilibria to this game are as follows:

- If $k>r$ there is a pure selection equilibrium in which Bad types never give high effort. In this equilibrium, incumbents are retained if $y_{2}=1$. Incumbents with bad traits are never retained if $y_{2}=0$ and those with good traits are retained when $y_{2}=0$ if and only if $q \geq \frac{1}{2-r}$.

- If $k \leq r$ and $q \geq \frac{1}{2-r}$ there is a partial accountability equilibrium in bad incumbents with good traits never give high effort and bad incumbents with bad traits give high effort with probability $\frac{1-q}{q}$. In this equilibrium, incumbents with good traits are always retained. Incumbents with bad traits are retained with probability $\frac{k}{r}$ when $y_{2}=1$ and are never retained when $y_{2}=0$.

- If $k \leq r$ and $q<\frac{1}{2-r}$ there is an accountability equilibrium. In this equilibrium, strategies following the selection of a candidate with bad traits are the same as the partial accountability equilibrium. 
Incumbents with good traits give high effort with probabiity $\frac{2 q-r q-1}{(q-1) r}$, are always retained when $y_{2}=1$, and are retained following $y_{2}=0$ with probability $\frac{r-k}{r}$.

Pure selection equilibria occur when the cost of effort is too high relative to any electoral benefit to motivate politicians to work hard. Since voters can only condition on outcomes and not directly on effort, the most a politician can increase her probability of reelection through effort is $r$, the probability of good outcomes given high effort. Thus, if $k>r$ then there is never an incentive to give high effort.

If $k<r$ then it is possible to support an equilibrium with some accountability. These equilibria are typically in mixed strategies. The reason for this is as follows. Suppose the voter always rewarded good outcomes by retaining the incumbent and punishes bad outcomes by removing the incumbent. If $k<r$ then giving high effort rather than low effort would increase the incumbent's probability of being retained by exactly $r$, which means both types would always strictly prefer to give high effort. However, if both types of incumbent always give high effort then outcomes are not informative at all about candidate types. Thus, the voter's best response would be to retain all incumbents with good traits and remove all incumbents with bad traits. Thus, there cannot be a pure strategy equilibrium in which Bad types ever give high effort if $k<r$.

The nature of a mixed strategy equilibrium with accountability depends on the candidate's traits. If the candidate has bad traits and the observed outcome is also bad $\left(y_{2}=0\right)$, the voter has two negative pieces of information about that incumbent and will not retain her. Likewise, if the candidate has good traits and the observed outcome is also good $\left(y_{2}=1\right)$ then the voter is certain to retain that incumbent. A mixed strategy equilibrium is one in which the incumbent's effort strategy leaves the voter indifferent between retaining and replacing the incumbent in the event that these signals conflict (i.e. $y_{2}=1$ under an incumbent with bad traits or $y_{2}=0$ under an incumbent with good traits). In turn, the voter's retention strategy leaves the bad type of incumbent indifferent between giving low and high effort. In Proposition 1, an accountability equilibrium is one in which this mixed strategy profile is played whether the incumbent has good or bad traits. A partial accountability is one in which the mixed strategy equilibrium is played when the incumbent has bad traits and the pure selection profile is played when the incumbent has good traits.

\subsection{First-period vote choice: When is bad news good?}

The analysis of effort and retention choices sets up a trade-off regarding candidate traits. Candidates with good traits are more likely to be Good types. However, since it is harder for the voter to commit to throwing 
out incumbents that produce bad outcomes when they have good traits, Bad types who happen to have good traits will be less accountable. This trade-off sometimes causes the voter to prefer candidates with bad traits over those with good traits despite the fact that these candidates are less likely go be Good types. I will refer to this phenomenon as negative selection.

\subsubsection{Equilibrium vote choice and negative selection}

Negative selection relates to the trade-off between selection and accountability. Thus, in a pure selection equilibrium there is no trade-off and good traits are always preferred. Otherwise, the voters' preference depends on the relative informativeness of traits versus outcomes as well as the proportion of Good types in the population. The result is states in Proposition 2 and proven in the appendix. The equilibrium vote choice follows directly from Proposition 2 and the assumption the voter breaks ties by flipping a fair coin.

Proposition 2. Let $_{P A}^{*}(p)=\frac{2 p^{2}-p+1}{(1-2 p)^{2}}-\sqrt{2} \sqrt{\frac{p}{(1-2 p)^{4}}}$ and $r_{A}^{*}(p, q)=\frac{2 p q-p-q}{2 p^{2} q-p^{2}-p q-1}$. In a pure selection equilibrium the voter always prefers candidates with good traits. A partial accountability equilibrium exhibits negative selection if and only if $q<q_{P A}^{*}(p)$.. An accountaiblity equilibrium exhibits negative selection if and only if $r<r_{A}^{*}(p, q)$.

Proposition 2 establishes that there exist parameters under which the voter prefers the candidate least likely to be a Good type. The intuition behind the result is that the observation that a candidate has good traits has two effects on the voter. The first is a direct effect: candidates with good traits are more likely to be Good types and the voter strictly prefers to elect Good types. The second effect is indirect and negative: a candidate with good traits knows that the voter believes she is more likely to be a good type, so Bad types who happen to have good traits will have less of an incentive to act in the best interests of the voter. Proposition 2 tells us that this indirect effect sometimes dominates the direct effect, causing the voter to prefer candidates with bad traits.

\subsubsection{Comparative statics}

To expand on the empirical implications of Proposition 2 we summarize in Proposition 3 how the incentive for negative selection depends on the primitives of the model. The parameters are the cost of effort $(\mathrm{k})$, the likelihood of observing a good outcome given high effort (r), the informativeness of traits (q), and the prior probability of a good type (p). 
The effect of effort costs is straightforward: if $k$ is large enough then Bad types will not give high effort and voters always prefer candidates with Good traits. The informativeness of traits (q) and effort (r) affect negative selection in a more complex way. If $r$ is sufficiently low (i.e. lower than $k$ ) then accountability is precluded for all candidates so negative selection is not beneficial. Furthermore, if $r$ is sufficiently large then reelection concerns will lead to effective accountability even for Bad types with good traits, so negative selection is not beneficial. Between those two extremes the voter may expect considerably more accountability for incumbents with bad traits than those with good traits and may therefore opt to select on bad traits. Similarly, if $q$ is close to one half and $r$ is reasonably large then traits do not provide enough information to overshadow the incumbents performance so they do not create enough accountability problems to lead to negative selection. If $q$ is close to one then traits screen candidate types so well that the voter is unconcerned about the rare event that traits give the wrong impression about the candidate's type. However, if $q$ is informative enough to cause accountability problems but not informative enough to lead to efficient screening, the voter may benefit from negative selection.

The final prediction concerns the proportion of Good types in the candidate pool (p). Negative selection is weakly more likely as $p$ decreases, meaning that as the proportion of Bad candidates gets large the voter is weakly more likely to favor candidates more likely to be Bad. Outside of the model this prediction may seem counterintuitive. For instance, it may seem like voters should be even more diligent about screening out corruption when corruption is rampant. However, the prediction is sensible in the context of this model because the voter is concerned both with selection and with accountability. In fact, when most politicians are corrupt, accountability is the more important effect of elections from the voter's perspective. Thus, for small values of $p$ the voter is more focused on the indirect effects of traits on accountability and may therefore benefit from engaging in negative selection.

Proposition 3. The likelihood of negative selection weakly decreases as $k$ and $p$ increase. Furthermore, the likelihood of negative selection depends nonmonotonically on $q$ and $r$.

The main results are summarized in Figure 1 which shows how the equilibria depend on the parameters $r$ and $q$ for several values of $p$ and with $k$ held constant at $\frac{1}{3}$. The probability of drawing a Good type of politician (p) does not affect the type of equilibrium played started in the second period though it does affect the effort probabilities within the mixed strategy equilibria. The gray region in each plot shows when negative selection occurs at the parameter values. The figures illustrate several results. First, the effect of 


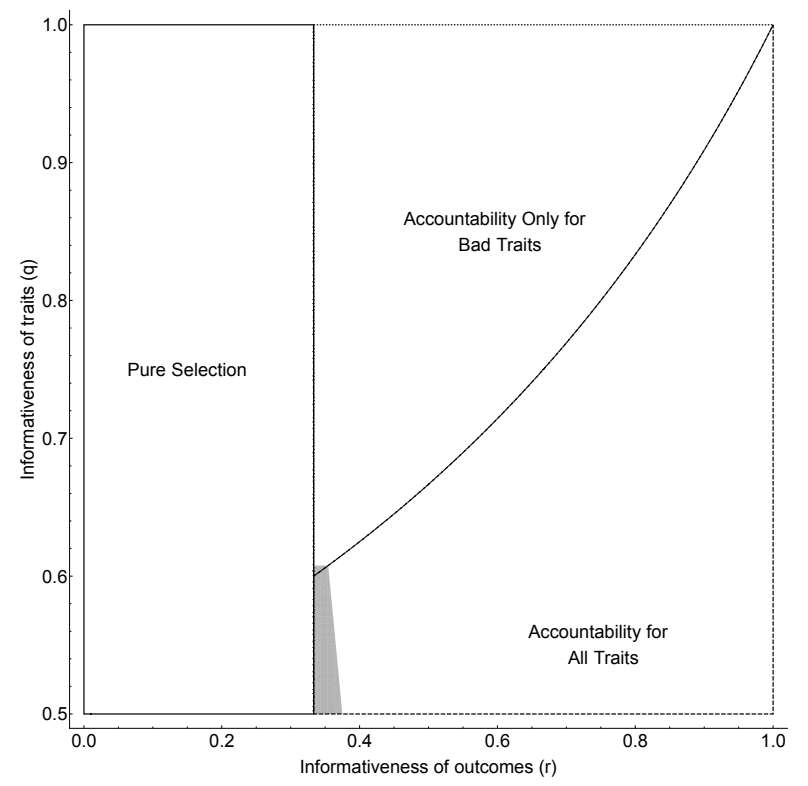

(a) $p=\frac{2}{3}$

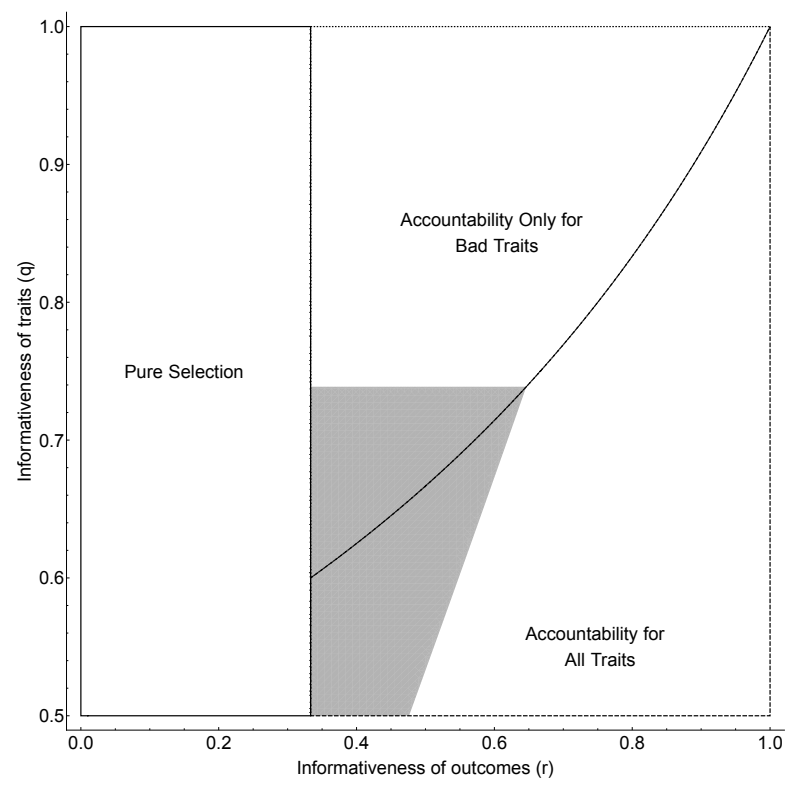

(c) $p=\frac{1}{10}$

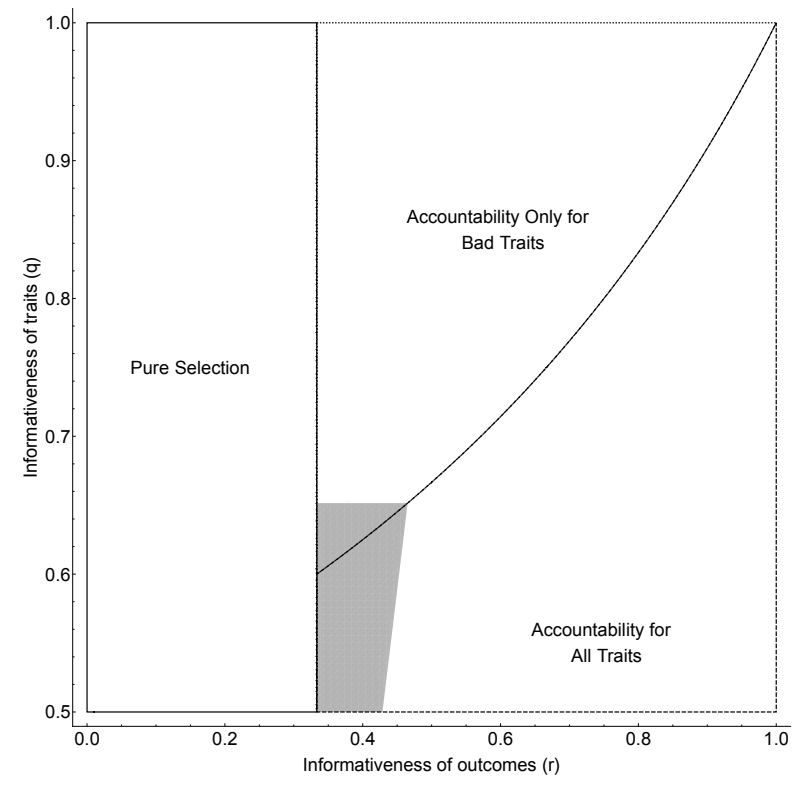

(b) $p=\frac{1}{3}$

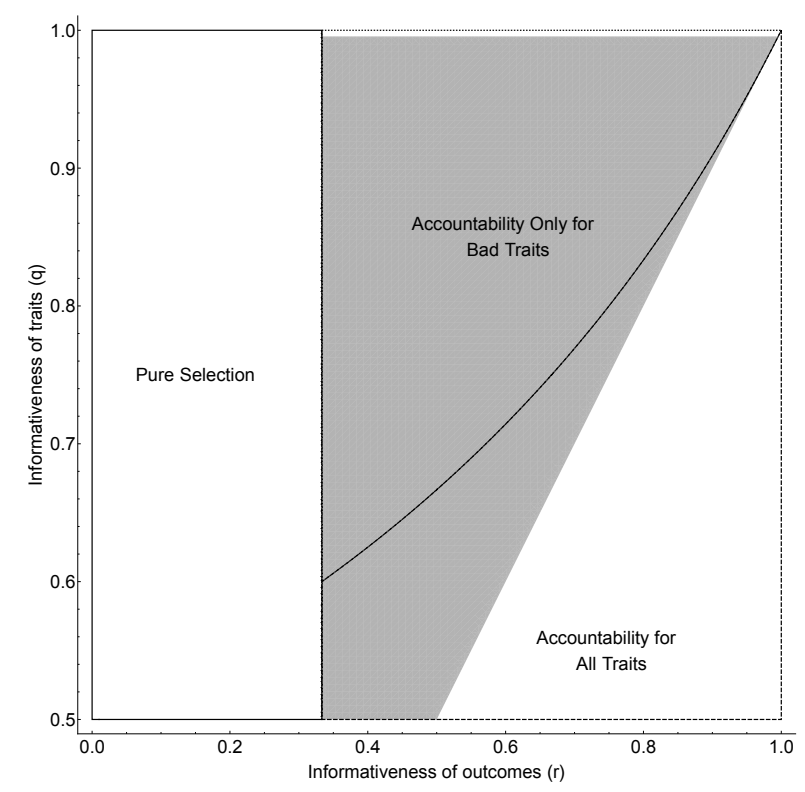

(d) $p$ near zero.

Figure 1: Visualization of equilibria for selected values of $p$ with $k$ held constant at $\frac{1}{3}$. The black lines separate regions with different types of equilibria to the second-period continuation game. The grey region is the region in which negative selection occurs. 
increasing the informativeness of traits (q) or the dependence of observed outcomes on effort (r), holding everything else constant, is ambiguous. Negative selection will not occur at the maximum values of $r$ and $q$ except when the prior probability of a Good politician is very close to zero, but local increases in either $q$ or $r$ could either cause or eliminate negative selection depending on the situation.

Second, negative selection is more common when $p$ is small. In the limiting case where $p$ is very close to zero, negative selection naturally holds in any partial accountability equilibrium. In the limiting case case the condition for negative selection in a partial accountability equilibrium becomes $q<\lim _{p \rightarrow 0} q_{P A}^{*}(p)=1$. and in a large portion of the parameter space for full accountability equilibria.In the limiting case the condition for negative selection in an accountability equilibrium becomes $r<\lim _{p \rightarrow 0} r_{A}^{*}(p, q)=q$. The implication of this last result is that negative selection in an accountability equilibrium only occurs when traits are more informative than incumbent performance. For instance, this may occur when voters place a lot of wieght on previous experience in office but performance outcomes are noisy or malfeasance is hard to detect.

\section{Discussion and applications}

We have analyzed a simple political agency model to explain how voters may select untried politicians for office on the basis of traits that are correlated with good performance in office. The model illustrates that these traits are not always desirable from the voter's perspective despite their association with good performance. The reason is that traits have an inderect effect on accountability and voters may find it hard to commit to firing incumbents who perform poorly but whose traits signal that they are good politicians. We conclude by discussing two applications that illustrate the potential usefulness of the model.

Corruption. We first describe how the model applies to the problem of corruption. Suppose Bad types are those attracted to corruption opportunities and High effort is interpreted as abstention from corruption, with the rents gained from corruption described by $k>0$. Traits may refer to any characteristics known to be associated with lower corruption. One type of trait may be the candidate's history: bad traits may include association with certain industries or criminal organizations and good traits may include a good record in public service. Additionally, behavioral research has shown that female, older, and less wealthy are more averse to corruption (Gatti, 2003) so voters may update based on this information. The parameter $r$ may be related to how economic indicators respond to corruption but may also be related to policy variables such 
as government audits (e.g. Avis, Ferraz and Finan, 2016) or some other mechanism for providing voters information on incumbents. ${ }^{5}$

Consider two societies that differ only with respect to the proportion of corrupt politicians in the candidate pool. Propositions 2 and 3 imply that the high-corruption society will be more likely to engage in negative selection when selecting among untried challengers but will be much harsher on incumbents, more often removing even high performing incumbents. Voters in low-corruption society will be unlikely to engage in negative selection in the first stage but incumbents on average will have an easier time getting reelected. Therefore, we may expect strong selection on candidate characteristics and high incumbency reelection rates in advanced democracies with low corruption but weak selection on characteristics and low incumbency reelection rates in developing countries with high corruption. The result shows how the selection of corrupt politicians is reinforced when corruption is perceived to be common: the voters' pessimism may lead them to reject politicians who they believe are less likely to be corrupt.

Judicial elections. Another application of the model is to the literature on judicial elections. In this literature, selection on candidate traits has been taken as a measure of voter attentiveness. For instance Hall and Bonneau (2006) find that candidate quality measures (i.e. previous office experience) affect voters choices in state supreme court elections and conclude that their findings "stand in stark relief to traditional notions that voters are incapable of responding to candidate stimuli beyond incumbency...” (p. 20). In contrast, Streb and Frederick (2009) find that candidate quality does a poor job at predicting outcomes in intermediate appellate court elections and conclude that, if the measure of candidate quality is valid, then voters must be unsophisticated or inattentive to these elections (p. 532). The model in this paper points to other explanations for these differences that do not depend on voter attentiveness. For instance, the same measure of candidate quality would have different effects on an attentive and rational electorate depending on the nature of the pool of candidates and the ability of voters to monitor incumbent performance.

\footnotetext{
${ }^{5}$ One difficulty in interpreting $r$ in relation to audits or informaiton provision is that in those examples the voters likely care about the politician's action whether or not it is reflectedin observed payoffs, where in the model the voter's utility is only affected by the observed outcomes. However, none of the results change if the voter's utility depends directly on actions rather than observed outcomes, so this change in interpretation is harmless.
} 


\section{References}

Ashworth, Scott. 2005. "Reputational Dynamics and Political Careers." Journal of Law, Economics, \& Organization 21(2):441-466.

Ashworth, Scott and Ethan Bueno de Mesquita. 2014. "Is Voter Competence Good for Voters?: Information, Rationality, and Democratic Performance.” The American Political Science Review 108(3):565-587.

Avis, Eric, Claudio Ferraz and Frederico Finan. 2016. Do government audits reduce corruption? Estimating the impacts of exposing corrupt politicians. Technical report National Bureau of Economic Research.

Berganza, Juan Carlos. 2000. “Two Roles for Elections: Disciplining the Incumbent and Selecting a Competent Candidate." Public Choice 105(1/2):165-193.

Besley, Timothy. 2006. Principled Agents?: The Political Economy of Good Government. Oxford University Press.

Buisseret, Peter and Carlo Prato. 2016. "Electoral control and the human capital of politicians." Games and Economic Behavior 98:34 - 55.

URL: http://www.sciencedirect.com/science/article/pii/S0899825616300276

Carson, Jamie L., Erik J. Engstrom and Jason M. Roberts. 2007. "Candidate Quality, the Personal Vote, and the Incumbency Advantage in Congress." American Political Science Review 101(2):289?301.

Fearon, James D. 1999. Electoral Accountability and the Control of Politicians: Selecting Good Types versus Sanctioning Poor Performance. Cambridge Studies in the Theory of Democracy Cambridge University Press p. 55?97.

Gatti, Roberta Paternostro, Stefano Rigolini Jamele. 2003. Individual Attitudes toward Corruption: Do Social Effects Matter? The World Bank.

URL: https://elibrary.worldbank.org/doi/abs/10.1596/1813-9450-3122

Hall, Melinda Gann and Chris W. Bonneau. 2006. "Does Quality Matter? Challengers in State Supreme Court Elections.” American Journal of Political Science 50(1):20-33.

URL: http://www.jstor.org/stable/3694254 
Hirano, Shigeo and James M. Snyder. 2014. "Primary Elections and the Quality of Elected Officials." Quarterly Journal of Political Science 9(4):473-500.

Kartik, Navin and Richard Van Weelden. 2018. "Informative Cheap Talk in Elections." The Review of Economic Studies .

Streb, Matthew J. and Brian Frederick. 2009. "Conditions for Competition in Low-Information Judicial Elections: The Case of Intermediate Appellate Court Elections." Political Research Quarterly 62(3):523537.

URL: https://doi.org/10.1177/1065912908321698

Winters, Matthew S. and Rebecca Weitz-Shapiro. 2013. "Lacking Information or Condoning Corruption: When Do Voters Support Corrupt Politicians?" Comparative Politics 45(4):418-436.

URL: http://www.jstor.org/stable/43664074 


\section{Appendix}

\section{Proof of Proposition 1.}

Pure selection equilibria: Since voters can only condition on outcomes and not directly on effort, the most a politician can increase her probability of reelection through effort is $r$, the probability of good outcomes given high effort. Thus, if $k>r$, the equilibrium to the second-period game is a pure selection equilibrium. Since Bad types never give high effort in this equilibrium, observing $y_{2}=1$ is a sure sign that the incumbent is Good so any incumbent is retained in this case. If the incumbent has bad traits and $y_{2}=0$ then, since all available information points to the conclusion that the incumbent is Bad, the voter prefers to fire the incumbent in this case. Specifically, the voter's posterior belief at this information set is $\operatorname{Pr}\left[\theta_{j}=G \mid s_{j}=b, y_{2}=0\right]=\frac{p(1-q)(1-r)}{p(1-q)(1-r)+(1-p) q}$ which is easily shown to be less than $p$ for all $r \in(0,1)$ and $q>\frac{1}{2}$. However, if $y_{2}=0$ and the incumbent has good traits, the outcome depends on whether traits are more informative to the voter than outcomes. The voter's belief at this information set is

$$
\operatorname{Pr}\left[\theta_{j}=G \mid s_{j}=g, y_{2}=0\right]=\frac{p q(1-r)}{p q(1-r)+(1-p)(1-q)}
$$

It is easy to show that this belief is greater than the prior belief $p$ when $q>\frac{1}{2-r}$.

Partial accountability equilibria: The argument in text shows why an equilibrium must be in mixed strategies. Indifference for Bad types of incumbents with bad traits, given that they will never be retained when $y_{2}=0$, means that

$$
r \sigma_{V}^{2}(b, 1)-k=0
$$

which is satisfied by $\sigma_{V}^{2}(b, 1)=\frac{k}{r}$. The voter is indifferent between retaining and replacing and incumbent with bad traits after observing $y_{2}=1$ if his posterior belief that the incumbent is a good type is exactly equal to $p$ :

$$
\operatorname{Pr}\left[\theta_{j}=G \mid s_{j}=b, y_{2}=1\right]=\frac{p(1-q) r}{(1-p) q r \sigma_{B}(b)+p(1-q) r}=p
$$

which holds if $\sigma_{B}(b)=\frac{1-q}{q}$. It follows from the argument for the pure selection equilibrium that the voter will always retain a candidate with good traits and, therefore, that Bad types with good traits will give low 
effort.

Accountability equilibria: The argument for candidates with bad traits follows from the analysis above. For candidates with good traits, ad type of incumbent with good traits is indifferent between giving high and low effort if

$$
(1-r)\left(\sigma_{V}^{2}(g, 0)-k\right)+(1-k) r=\sigma_{V}^{2}(g, 0)
$$

which holds if $\sigma_{V}^{2}(g, 0)=\frac{r-k}{r}$. The voter is indifferent over whether to retain or replaces an incumbent with good traits after observing $y_{2}=0$ if

$$
\operatorname{Pr}\left[\theta_{j}=G \mid s_{j}=g, y_{2}=0\right]=\frac{p q(1-r)}{(1-p)(1-q)(1-r) \sigma_{B}(g)+p q(1-r)+(1-p)(1-q)\left(1-\sigma_{B}(g)\right)}=p
$$

which holds if $\sigma_{B}(g)=\frac{2 q-r q-1}{(q-1) r}$.

Proof of Proposition 2. First we consider the accountability equilibrium. We define $U_{V}^{A}\left(\theta_{j}, s_{j}\right)$ to be the voter's value for electing a candidate with type $\theta_{j}$ and traits $s_{j}$ in an accountability equilibrium. These are:

$$
\begin{aligned}
& U_{V}^{A}(G, g)=(1-r)\left(p r\left(1-\frac{r-k}{r}\right)+\frac{r-k}{r} r+0\right)+r(r+1) \\
& U_{V}^{A}(B, g)=\frac{2 q-r q-1}{(q-1) r}\left(r(1+0)+(1-r)\left(1-\frac{r-k}{r} p r\right)\right)+\left(1-\frac{2 q-r q-1}{(q-1) r}\right)\left(1-\frac{r-k}{r} p r\right) \\
& U_{V}^{A}(G, b)=r\left(1+\left(1-\frac{k}{r}\right) p r+\frac{k}{r} r\right)+(1-r) p r \\
& U_{V}^{A}(B, b)=\frac{1-q}{q}\left(r\left(1+\left(1-\frac{k}{r}\right) p r\right)+(1-r) p r\right)+\left(1-\frac{1-q}{q}\right) p r .
\end{aligned}
$$

The voter observes characteristics but not types and believes candidates with each set of trait to be Good with probabilities:

$$
\begin{aligned}
& \operatorname{Pr}\left[\theta_{j}=G \mid s_{j}=g\right]=\frac{p q}{(1-p)(1-q)+p q} \\
& \operatorname{Pr}\left[\theta_{j}=G \mid s_{j}=b\right]=\frac{p(1-q)}{p(1-q)+(1-p) q} .
\end{aligned}
$$

Putting this together, the voter's value for selecting a candidate with traits $s_{j}$, which we will define as $\bar{U}_{V}^{A}\left(s_{j}\right)$, 


$$
\begin{aligned}
& \bar{U}_{V}^{A}(g)=\frac{p q}{(1-p)(1-q)+p q} U_{V}^{A}(G, g)+\left(1-\frac{p q}{(1-p)(1-q)+p q}\right) U_{V}^{A}(B, g) \\
& \bar{U}_{V}^{A}(b)=\frac{p(1-q)}{p(1-q)+(1-p) q} U_{V}^{A}(G, b)+\left(1-\frac{p(1-q)}{p(1-q)+(1-p) q}\right) U_{V}^{A}(B, b) .
\end{aligned}
$$

Solving

$$
\bar{U}_{V}^{A}(b)>\bar{U}_{V}^{A}(g)
$$

for $r$ yields $q<\frac{p^{2} r-p+r}{(2 p-1)(p r-1)}$.

Second we consider the partial accountability equilibrium. We define the voter's value for each type, denoted $\bar{U}_{V}^{P A}\left(s_{j}\right)$ as before. Note that this equilibrium is identical for candidates with bad traits, so $\bar{U}_{V}^{P A}(b)=$ $\bar{U}_{V}^{A}(b)$. Furthermore, since only the Good types of candidates with good traits ever give high effort, we have:

$$
\left.\bar{U}_{V}^{P A}(g)=\frac{p q}{(1-p)(1-q)+p q}((1-r)(r+0)+r(r+1))\right) .
$$

Solving

$$
\bar{U}_{V}^{P A}(b)>\bar{U}_{V}^{P A}(g)
$$

for $\mathrm{r}$ yields $r<\frac{2 p q-p-q}{2 p^{2} q-p^{2}-p q-1}$.

Finally, consider a pure selection equilibrium. Since only Good types give high effort and those who give high effort are more likely to be retained, it follows from the fact that $\operatorname{Pr}\left[\theta_{j}=G \mid s_{j}=g\right]>\operatorname{Pr}\left[\theta_{j}=G \mid s_{j}=b\right]$ that candidates with good traits are preferred.

Proof of Proposition 3. Increasing $k$ can only affect the likelihood of negative selection by inducing a pure selection equilibrium in which negative selection never occurs. Nonmonotoncity in $q$ and $r$ follows from the analysis in text. To prove that the likelihood of negative selection is weakly decreasing in $p$ note first that second-period equilibrium selection does not depend on $p$. Thus, the result follows directly from comparative statics on the cutpoints $q_{P A}^{*}(p)$ and $r_{A}^{*}(p, q)$.

We have

$$
\frac{\partial r_{A}^{*}(p, q)}{\partial p}=\frac{1-(-2 p q+p+q)^{2}-2 q+1}{(p(-2 p q+p+q))^{2}}<0
$$

where the inequality is evident from the fact that $2 q>1$. Thus, as $p$ increases we must have smaller values 
of $r$ to support negative selection in an accountability equilibrium. Furthermore, we have

$$
\frac{\partial q_{P A}^{*}(p)}{\partial p}=-\frac{2}{\sqrt{p}(2 \sqrt{p}+\sqrt{2})^{3}}<0
$$

so as $p$ increases we must have smaller values of $q$ to support negative selection in a partial accountability equilibrium. 